The University of Maine

\title{
DigitalCommons@UMaine
}

Earth Science Faculty Scholarship

Earth Sciences

$11-30-1997$

\section{Electrical Measurements on the Greenland Ice Sheet Project 2 Core}

\author{
Kendrick C. Taylor \\ Richard B. Alley \\ Gregg W. Lamorey \\ Paul Andrew Mayewski \\ University of Maine, paul.mayewski@maine.edu
}

Follow this and additional works at: https://digitalcommons.library.umaine.edu/ers_facpub

Part of the Glaciology Commons, and the Hydrology Commons

\section{Repository Citation}

Taylor, Kendrick C.; Alley, Richard B.; Lamorey, Gregg W.; and Mayewski, Paul Andrew, "Electrical Measurements on the Greenland Ice Sheet Project 2 Core" (1997). Earth Science Faculty Scholarship. 261.

https://digitalcommons.library.umaine.edu/ers_facpub/261 


\title{
Electrical measurements on the Greenland Ice Sheet Project 2 Core
}

\author{
Kendrick C. Taylor, ${ }^{1}$ Richard B. Alley, ${ }^{2}$ Gregg W. Lamorey, ${ }^{1}$ and Paul Mayewski ${ }^{3}$
}

\begin{abstract}
The Greenland Ice Sheet Project 2 (GISP2) electrical conductivity measurement (ECM) record is an indication of the concentration of $\mathrm{H}+$ in the core. The ECM detected seasonal variations in the nitrate concentration of the core which were used to assist in dating the core by annual layer counting. Volcanic eruptions that produce acidic aerosols are recorded in the ECM record. Evidence of biomass burning is detected by the ECM because fire-related ammonium emissions neutralize the acids in the core. Rapid climate transitions associated with the Younger Dryas and Dansgaard/Oeschger interstadial events alter the concentration of alkaline dust and are detected by the ECM. The ECM has been used to develop stratigraphic ties between the GISP2 and the Greenland Ice Core Project cores. Users of the data should be aware of some instrumentrelated artifacts in the ECM record.
\end{abstract}

The Greenland Ice Sheet Project 2 (GISP2) ice core contains a stratified sequence of precipitation which has been used to obtain paleoclimate information. A wide variety of measurements have been made to determine the physical, chemical, and isotopic characteristics of the ice, particulates, and gases in the core. The electrical conductivity measurement (ECM) measures the direct current between two electrodes with a potential difference of several thousand volts [Hammer, 1980; Taylor et al., 1992]. The electrodes are moved along the surface of the core, and a continuous measurement of the ECM current along the core is obtained. In an aqueous solution, all the ions can participate in the conduction of an electrical charge. In ice the movement of the ions is restricted by the ice lattice which reduces the ability of the ions to conduct a direct current. The direct current is conducted by the movement of protons associated with the $\mathrm{H}+$ of strong acids; hence the ECM current is considered to be a measure of the acidity of the ice [Hammer, 1980; Moore et al., 1992; Taylor et al., 1992]. The ECM has a spatial resolution of $<10 \mathrm{~mm}$ yet is rapid enough that it is practical to measure it continuously along the entire core. These attributes make the ECM ideally suited for investigation of short-duration phenomena which influence the acid/base balance of the ice.

Two-meter sections of the core were passed under a horizontal band saw to remove a 50-mm-wide slab along the axis of the core. A rail-mounted microtome knife or milling machine was used to shave the saw cut surface to remove surface contamination and surface irregularities. A computer controlled the motion of electrodes along the axis of the core and recorded the ECM current for each millimeter of travel [Taylor et al., 1992]. The operator used a hand switch to identify portions of the measurement which where invalid. Examples of

\footnotetext{
${ }^{1}$ Desert Research Institute, University and Community College Systerm of Nevada, Reno.

${ }^{2}$ Earth System Science Center and Department of Geosciences, Pennsylvania State University, University Park.

${ }^{3}$ Glacier Research Group, Institute for the Study of Earth, Oceans and Space, University of New Hampshire, Durham.

Copyright 1997 by the American Geophysical Union.

Paper number 96JC02500.

$0148-0227 / 97 / 96 \mathrm{JC}-02500 \$ 09.00$
}

this include data from locations within $10 \mathrm{~mm}$ of a fracture in the core or when large surface irregularities prevented proper preparation of the ice surface. Data from these locations were removed from the data set. Fractures that did not penetrate through the core and had never had any exposed surfaces or open spaces did not seem to adversely influence the data and were included in the data set. The system used at the Greenland Ice Core Project (GRIP) [Wolff et al., 1995] was similar; however, the electrode geometry and voltage were different. This resulted in higher currents in the GISP2 ECM record than in the GRIP record. Intercomparisons of cores demonstrated that despite the different absolute values, the relative response of features is the same for the two systems.

Annual layer counting was used to date the most recent 40,000 years of the GISP2 core [Alley et al., 1993; Meese et al., 1994]. Several methods were used to identify annual layering, including visual observation of stratigraphy [Alley et al., 1993], aqueous phase particle concentration [Ram and Illing, 1994], optical properties of the ice [Ram and Koenig, this issue], concentration of major ions [Mayewski et al., 1993a], oxygen isotopes of the ice [Grootes et al., 1993], and ECM [Taylor et al., 1992]. Of these properties, only the visual stratigraphy and ECM are available for the entire core with a spatial resolution suitable for the investigation of annual layering. All available properties were used in a combined fashion to develop the age/depth scale for the core [Alley et al., 1993; Meese et al., 1994]. The current annual ice accumulation rate at the site is $0.24 \mathrm{~m} / \mathrm{yr}$ [Alley and Koci, 1990]. Lateral ice flow thins the annual layers at greater depth, resulting in annual layer thickness of less than $2 \mathrm{~cm}$ at a depth of $1900 \mathrm{~m}$ [Meese et al., 1994]. There is a pronounced seasonal variation in the chemistry of the precipitation, which influences the acid/base balance of the core [Mayewski et al., 1993a; Taylor et al., 1992]. In the Holocene portion of the core the dominant seasonal influence on the ECM current is seasonal variations in the nitrate budget (Figure 1a) [Neftel et al., 1985; Taylor et al., 1992]. In the stadial portion of the core, seasonal variations in dust dominate the ECM (Figure 1b), visual stratigraphy, and dust concentration measurements. Because these measurements are measuring a different attribute of the same seasonal phenomena (the dust concentration), they are not completely independent. Any me- 

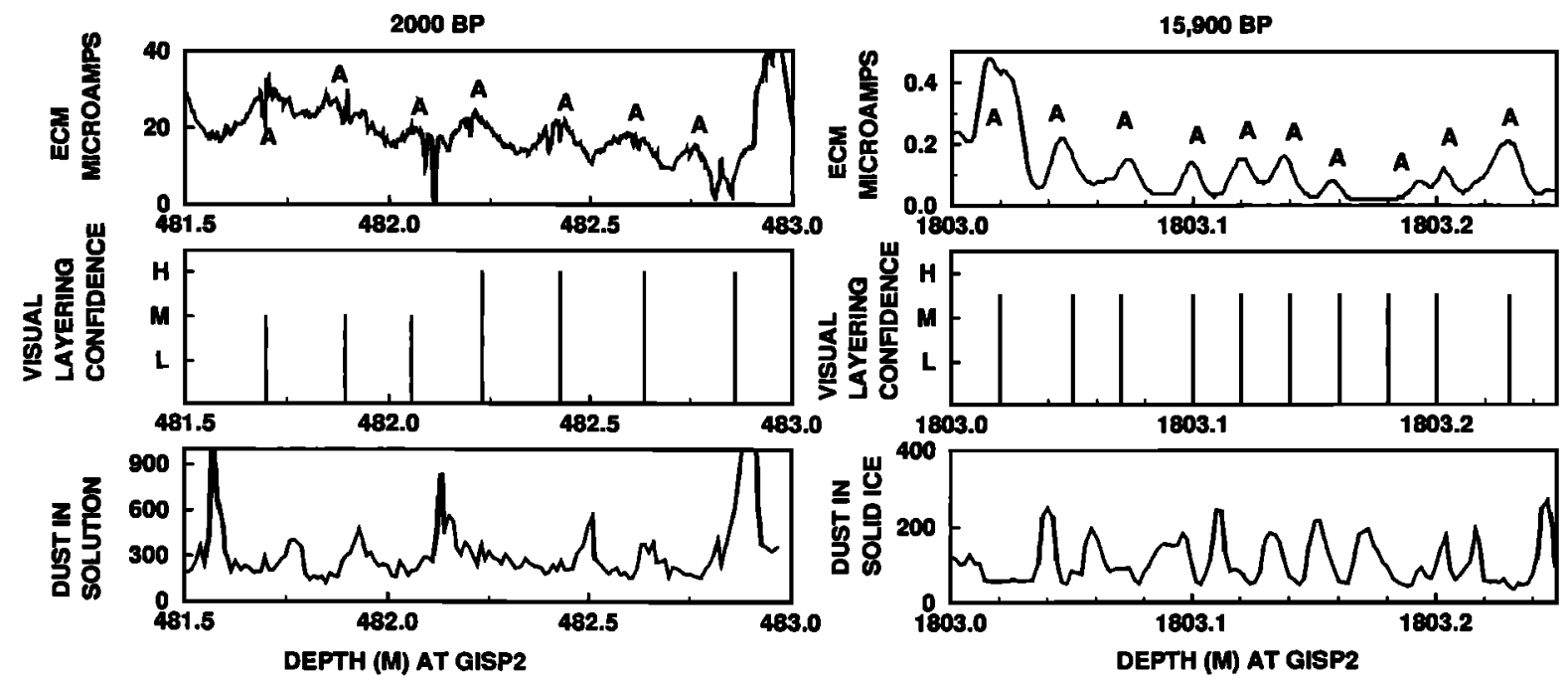

Figure 1. Annual layering is detectable in ice from (a) the Holocene and (b) portions of the Wisconsin. Alkaline dust in the stadial portions of the Wisconsin decreases the ECM value $>100$ times compared to Holocene values. Visual observation of the layering in the Holocene portion of the core is possible because of seasonal development of hoar frost, which influences the crystal size and fabric. The confidence of the interpretation of visual layering is indicated on the figures as high $(\mathrm{H})$, medium $(\mathrm{M})$, and low $(\mathrm{L})$. The dust concentration in sections of the Holocene was determined by $90^{\circ}$ scattering of laser light in a melted sample (Figure 1a); the dust concentration in sections of the Wisconsin was measured by $90^{\circ}$ scattering of laser light by an ice sample (Figure 1b) [Ram and Illing, 1994]. Interpreted annual layers are indicated by "A."

teorological or glaciological phenomena which adversely influence the seasonal dust signal will adversely influence all three of these records. The high spatial resolution of the ECM makes it well suited for identifying the annual layering. However, in some sections of the core the ECM is not well suited for the detection of annual layering because nonseasonal factors such as volcanic activity, biomass burning, and other poorly understood features reduce the clarity of the annual signal. When the annual layering is less than $15 \mathrm{~mm}$, the ECM is unable to adequately resolve annual layering with sufficient confidence to be useful for dating purposes. When the annual layer is less than $15 \mathrm{~mm}$, only visual stratigraphy was used for identification of the annual layering. This occurred below $2510 \mathrm{~m}$ (56 kyr B.P.).

Volcanic activity that emits $\mathrm{H}_{2} \mathrm{~S}$ and $\mathrm{SO}_{2}$ will increase atmospheric levels of $\mathrm{H}_{2} \mathrm{SO}_{4}$. Precipitation which forms in an air mass that has an elevated level of $\mathrm{H}_{2} \mathrm{SO}_{4}$ will have a corresponding increase in the concentration of $\mathrm{H}+$. The elevated $\mathrm{H}+$ will increase the ECM current. The ECM current may be elevated for several years, while the volcanic $\mathrm{H}_{2} \mathrm{SO}_{4}$ aerosols remain in the atmosphere. The influence of acidic volcanic activity on the ECM is identifiable by a large increase in the ECM current that extends for a period of less than a few years (Figure 2). The sulfate concentration was measured on the Holocene portion of the GISP2 core [Mayewski et al., 1993b; Zielinski et al., 1994] with a temporal resolution of approximately 2 years. The identification of volcanic eruptions has been used for developing stratigraphic ties between the GISP2 and GRIP cores and between the main GISP 2 core and several associated shallow cores. The sulfate record is well suited for developing a record of volcanic activity because it is chemically specific and hence is not influenced by nonsulfate-related processes which can mask the volcanic $\mathrm{H}+$ signal on the ECM record. The ECM is not sensitive to increases in sulfate that are not associated with $\mathrm{H}_{2} \mathrm{SO}_{4}$ and has greater temporal res- olution than the sulfate record. Occasionally, this allows the duration of the increased sulfate loading to be more accurately determined with the ECM than with the available biannually sampled sulfate data. It also allows short-duration volcanic events, which are attenuated in the biannual sulfate record, to be identified. A composite record that has the advantages of both the ECM and sulfate records can be developed. The volcanic record from GISP2 preferentially records regional volcanic eruptions, particularly those at high northern latitudes. The southern hemisphere eruption of Tambora (1815) was observed [Zielinski et al., 1994], and the eruption of Toba 71 kyr B.P. may have been identified [Zielinski et al., 1996].

Biomass burning introduces soot and other inorganic and organic material into the atmosphere. The introduction of ammonium into the atmosphere by biomass burning is of particular significance to the ECM. When precipitation occurs from an air mass that has an elevated level of ammonium, the ammonium level in the core will increase. This neutralizes some of the $\mathrm{H}+$ in the core or binds the $\mathrm{H}+$ into a less conductive state, which decreases the ECM current (Figure 3 ). The residence time for elevated ammonium levels associated with biomass burning is typically less than a week [Hov and Hjøllo, 1994]. The decrease in ECM current is of short duration and thought to be associated with deposition during a single storm. The large-amplitude, short-duration reductions in the ECM current associated with biomass burning during the Holocene portion of the core can be used to develop a record of the rate of occurrence of precipitation during periods when biomass burning influenced the atmospheric chemistry. The GISP2 biomass burning record is analogous to recording the number of days a year an observer at the site would have noted storms containing trace amounts of biomass burning byproducts. Although biomass burning events are evident in both the concentration of soot in the core [Chylek et al., 1995] and ammonium [Whitlow et al., 1994], these analyses were too labor 


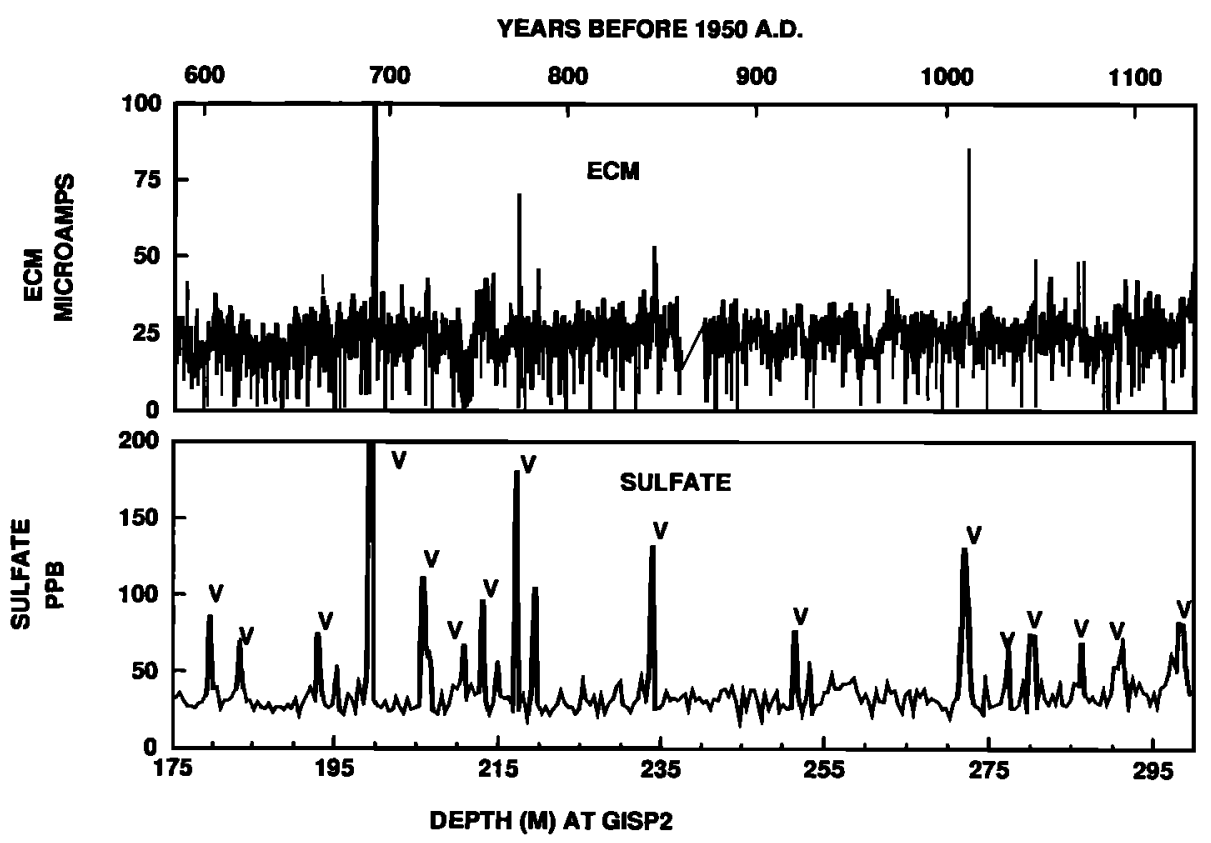

Figure 2. Volcanic activity can result in elevated levels of atmospheric $\mathrm{H}_{2} \mathrm{SO}_{4}$, which increases the ECM and sulfate concentrations in the core. Volcanic events identified by Zielinski et al. [1994] are indicated by "v." The volcanic events are not always as pronounced on the ECM as on the sulfate record because the ECM is influenced by other species besides $\mathrm{H}_{2} \mathrm{SO}_{4}$. A combination of coincident, short-duration increases on both the ECM and sulfate is an unambiguous indication of an increase in $\mathrm{H}_{2} \mathrm{SO}_{4}$.

intensive to be conducted with subannual resolution for the entire Holocene portion of the core. The ECM method does have the required subannual resolution and was used to suggest a fire history for the presumed eastern Canadian source area [Taylor et al., 1996].

During cold conditions (i.e., the Younger and Older Dryas, the Inter Allerod cold period, and the stadial portions of the Wisconsin glaciation), high concentrations of calcium carbonate dust altered the acid/base balance of the ice [Wolf et al., 1995]. The increased levels of calcium neutralized all or most of the $\mathrm{H}+$ ions and caused a $>100$ times decrease in the ECM current. The variations in wind-borne dust are associated with variations in the atmospheric transport of dust, indicating significant differences in atmospheric transport between stadial and interstadial conditions. The transition in atmospheric transport between stadial and interstadial conditions occurs

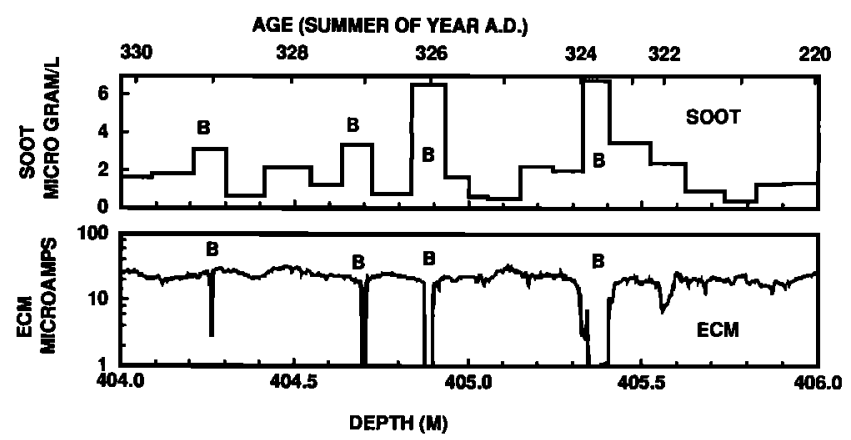

Figure 3. Biomass burning can result in the deposition of soot carbon [Chylek et al., 1995] and ammonium in the ice core. The ammonium neutralizes the $\mathrm{H}+$ ions and reduces the ECM. Biomass burning episodes recorded in the core are indicated as "B." rapidly, typically in less than 20 years. The calcium, accumulation, and ECM records suggest that the rapid transitions between climate states may be preceded by short-duration climate excursions ("flickers") (Figure 4) prior to the transition to an alternate, more stable climate state. The multiyear excursions may be the result of increased climate instability around the time of major climate transitions [Taylor et al., 1993a]. The ECM record clearly resolves the pattern of Wisconsin interstadial events which dominate the climate history of the North Atlantic during the Wisconsin and Holocene periods (Figure 5). The ECM record appears to indicate that interstadial, Allerod, and Bolling periods had greater climate variability than the Holocene. This artifact occurs because the ECM during this time period is at a level that is particularly sensitive to small changes in the acid/base balance.

The GRIP and GISP2 ice cores provide the opportunity to compare the spatial variability of the ice properties at various depths in the cores. Ice from a specific time period does not occur at the same depth in both cores because of differences in the accumulation rate and ice flow. Down to a depth of $2720 \mathrm{~m}$ at GISP2 and $2690 \mathrm{~m}$ at GRIP (Figure 6), the two cores can be unambiguously correlated by accounting for a slowly changing depth offset between the cores. Features as small as $0.2 \mathrm{~m}$ correlate unambiguously between the cores [Taylor et al., 1993b]. For the next $150 \mathrm{~m}$ below these depths, various combinations of stretching, compressing, and, possibly, folding must be invoked to develop a speculative correlation between the two cores. The cores have not been successfully correlated in the bottom 5\%. Millimeter-scale overturned folds were first observed at $2483 \mathrm{~m}$ at GRIP and $2437 \mathrm{~m}$ at GISP2. Layers inclined at $20^{\circ}$ to the axis of the cores were first observed at $2757 \mathrm{~m}$ at GRIP and $2679 \mathrm{~m}$ at GISP2 [Alley et al., 1995]. These small features may be associated with larger-scale distortions, which account for the poor correlation between the two cores 


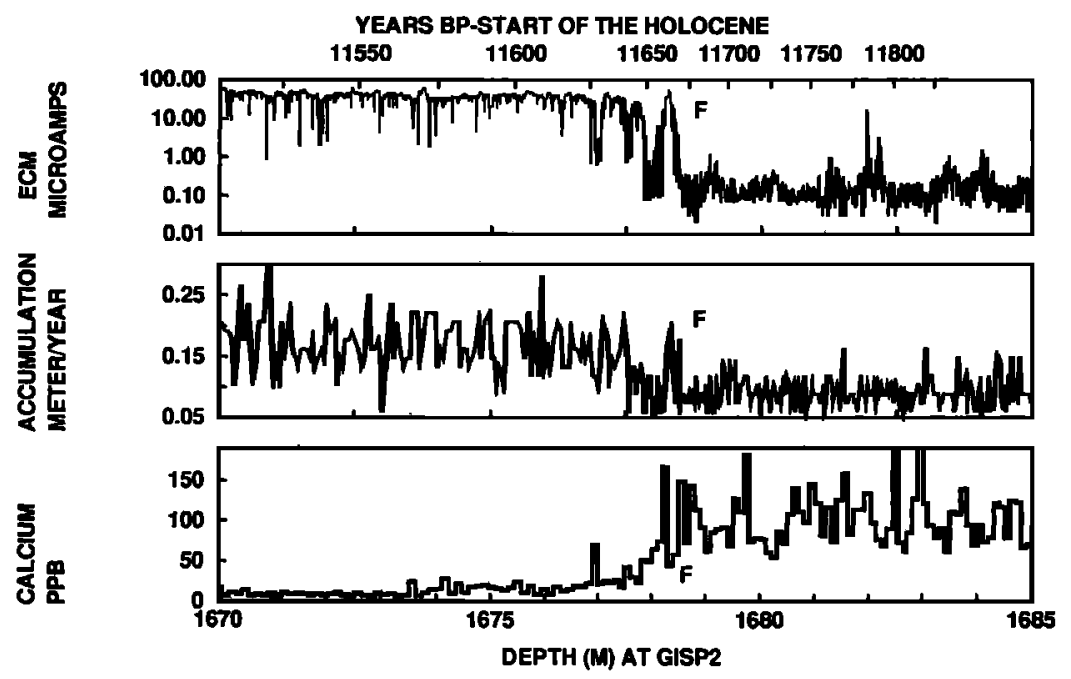

Figure 4. The climate transition at the start of the Holocene is accompanied by a rapid decrease in the concentration of calcium [Mayewski et al., 1994], which increases the ECM signal from the low value associated with alkaline Wisconsin age ice. There is also a rapid increase in the accumulation rate accompanying the climate transition [Alley et al., 1993]. The data suggest that the climate underwent a brief excursion or "flicker" (indicated by "F") prior to stabilizing at Holocene conditions.

in the bottom $10 \%$ of the cores. Interpretation of the climate signal in the lowest $10 \%$ of the cores must proceed with caution because the records are not reproducible [Taylor et al., 1993b].

Ice-penetrating radar has been used extensively to investi- gate the internal structure of ice sheets. Ice from different time periods has different chemical and hence electrical characteristics. The different electrical characteristics create abrupt transitions in electrical properties, which reflect radar signals.

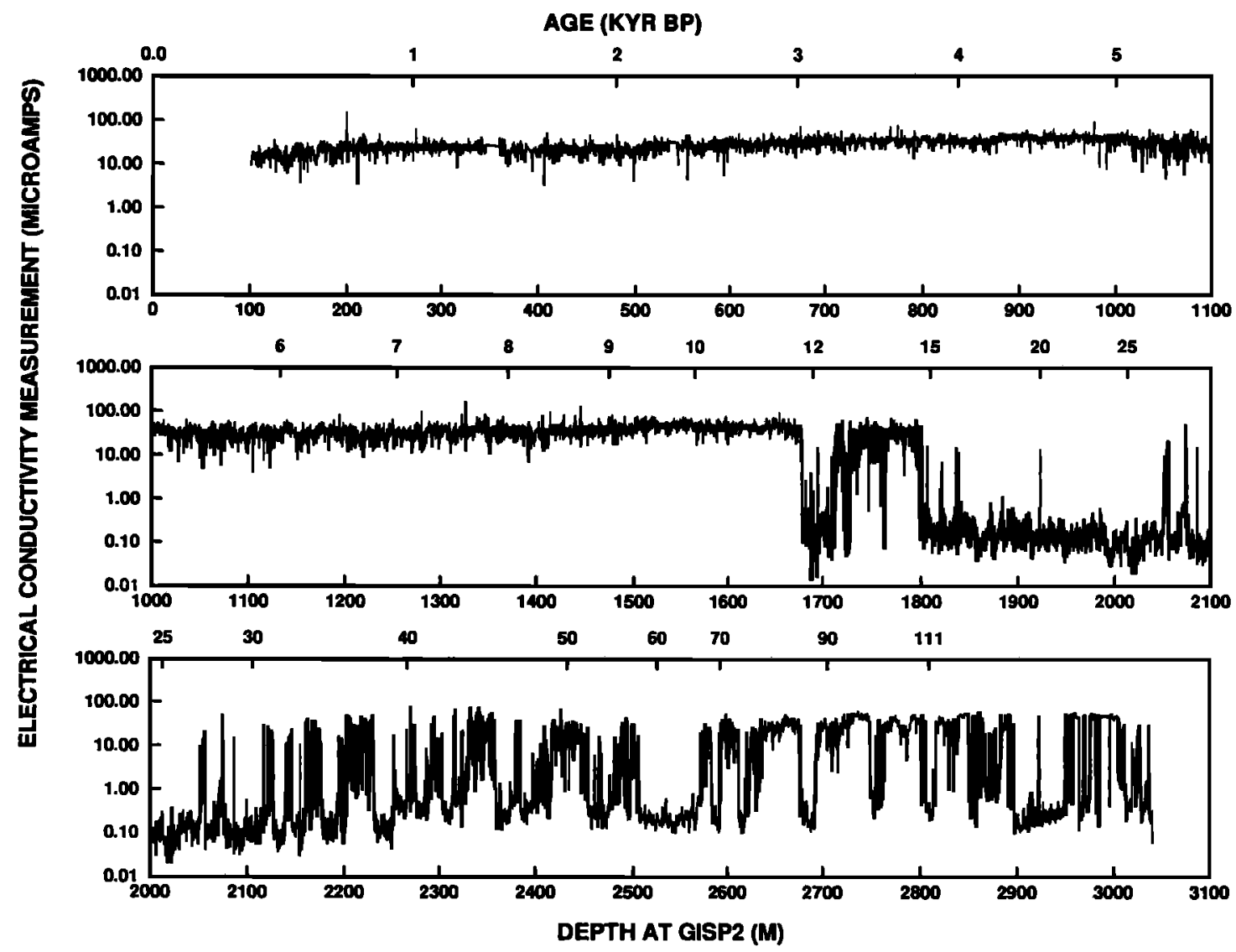

Figure 5. The ECM record for the GISP2 core shows climate excursions during the Wisconsin. The low ECM values are caused by increased levels of carbonate dust during the windy cold portions of the Wisconsin. Dating is from Meese et al. [1994] and T. Sowers (personal communication, 1995). 


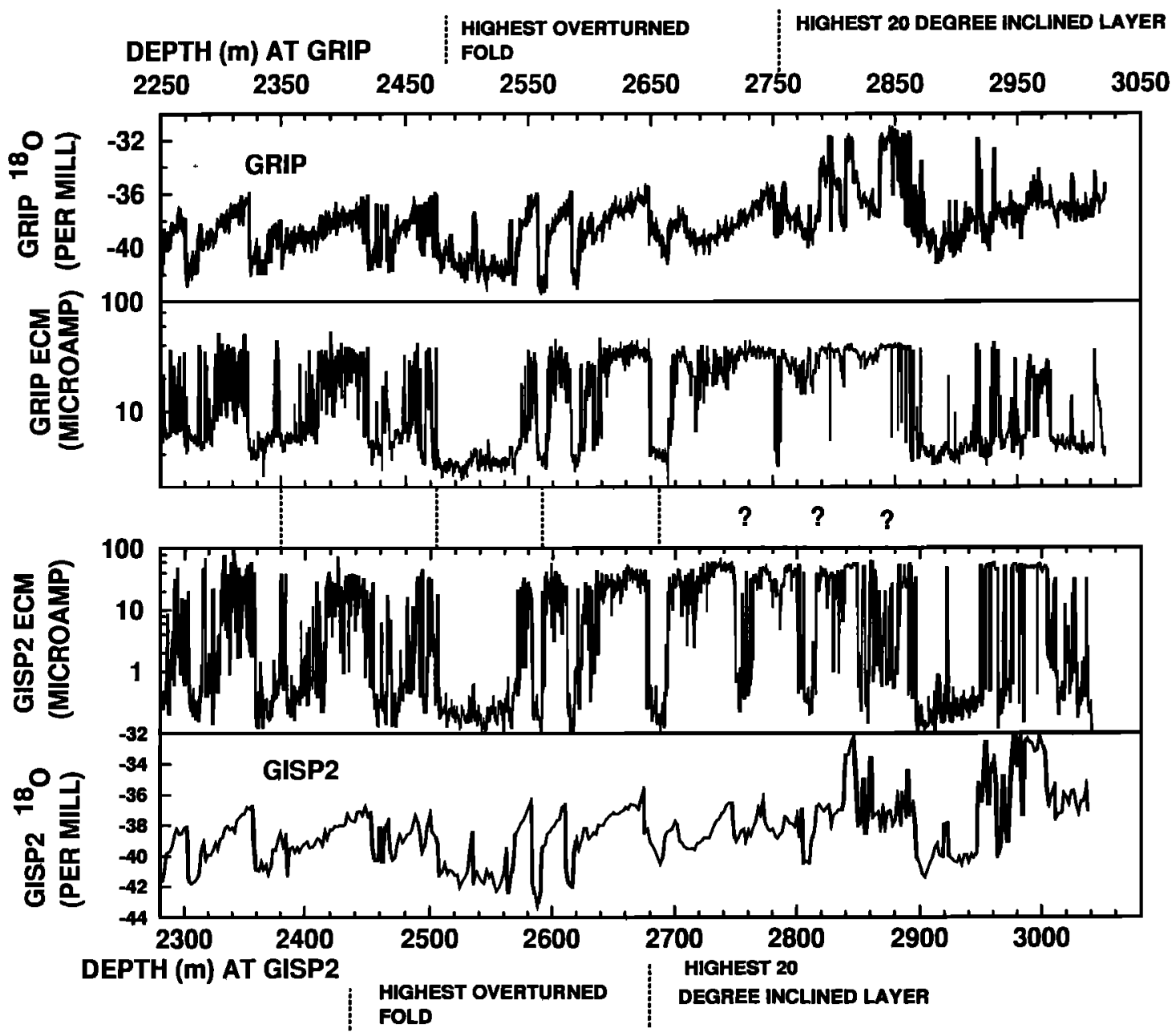

Figure 6. A comparison of the electrical and ${ }^{18} \mathrm{O}$ isotopic records from the GISP2 [Taylor et al., 1993b; Grootes et al., 1993] and GRIP [Dansgaard et al., 1993] cores demonstrates the excellent agreement of the stratigraphy above $2720 \mathrm{~m}$ at GISP2 and $2690 \mathrm{~m}$ at GRIP. Below this depth the records are not reproducible. The occurrence of visually observed stratigraphic features [Alley et al., 1995] is indicated. The magnitude of the ECM is different for the two cores because of instrumentation differences.

The reflectors can be profiled with surface or airborne radar systems so that a view of the internal structure of the ice can be developed. It is difficult to use the ECM to compute the radar reflection coefficients of the ice stratigraphy because the ECM only measures part of the frequency dependent complex electrical properties. This is particularly true in the alkaline ice, where the electrical conductivity is reduced by orders of magnitude more for the direct current used in the ECM than at the tens of megahertz used in radar measurements. A comparison of the ECM to the airborne radar measurements [Jacobel and Hodge, 1995] (Figure 7) shows that there are prominent radar reflections in the Holocene portion of the ice sheet associated with the transitions between alkaline and nonalkaline ice. In the alkaline ice, which can be identified by a low ECM, there are no prominent radar reflections. In the Summit region this produces a pronounced set of reflections probably associated with the Dansgaard/Oeschger interstadial events and a lack of prominent reflections immediately below the Allerod/Bolling periods. This attribute makes the radar useful for spatially mapping the depth of ice associated with these time intervals, which will be useful in stratigraphic studies and selecting future drilling sites. The ECM indicates that the contrasts in electrical properties, which generate the radar reflections, continue to the bed. The recorded reflections become much weaker near the bottom due to a decreasing signal to noise ratio associated with signal attenuation at greater depths or due to folding of the layer contacts which reduces the reflected signal coherency. This makes it difficult to use available radar data to investigate the stratigraphy of the bottom $10 \%$ of the ice sheet where the stratigraphic discrepancies occur between the GISP2 and GRIP cores [Jacobel and Hodge, 1995].

In intervals below $2800 \mathrm{~m}$, some crystals exceed $50 \mathrm{~mm}$ in length. The crystal boundaries could be visually observed on the surface of the core due to differences in sublimation rate. The crystals were sufficiently large that the electrodes frequently were several centimeters from a crystal boundary and would also cross distinct contacts between two crystals. The crystal boundaries were not associated with any notable feature in the ECM record, indicating that the crystal boundaries were not significant preferred paths for electrical conduction.

Instrument-related artifacts adversely influence some aspects of the GISP2 ECM record. The ECM current is influenced by the temperature of the ice when the measurement was made. A correction based on the surface temperature of 

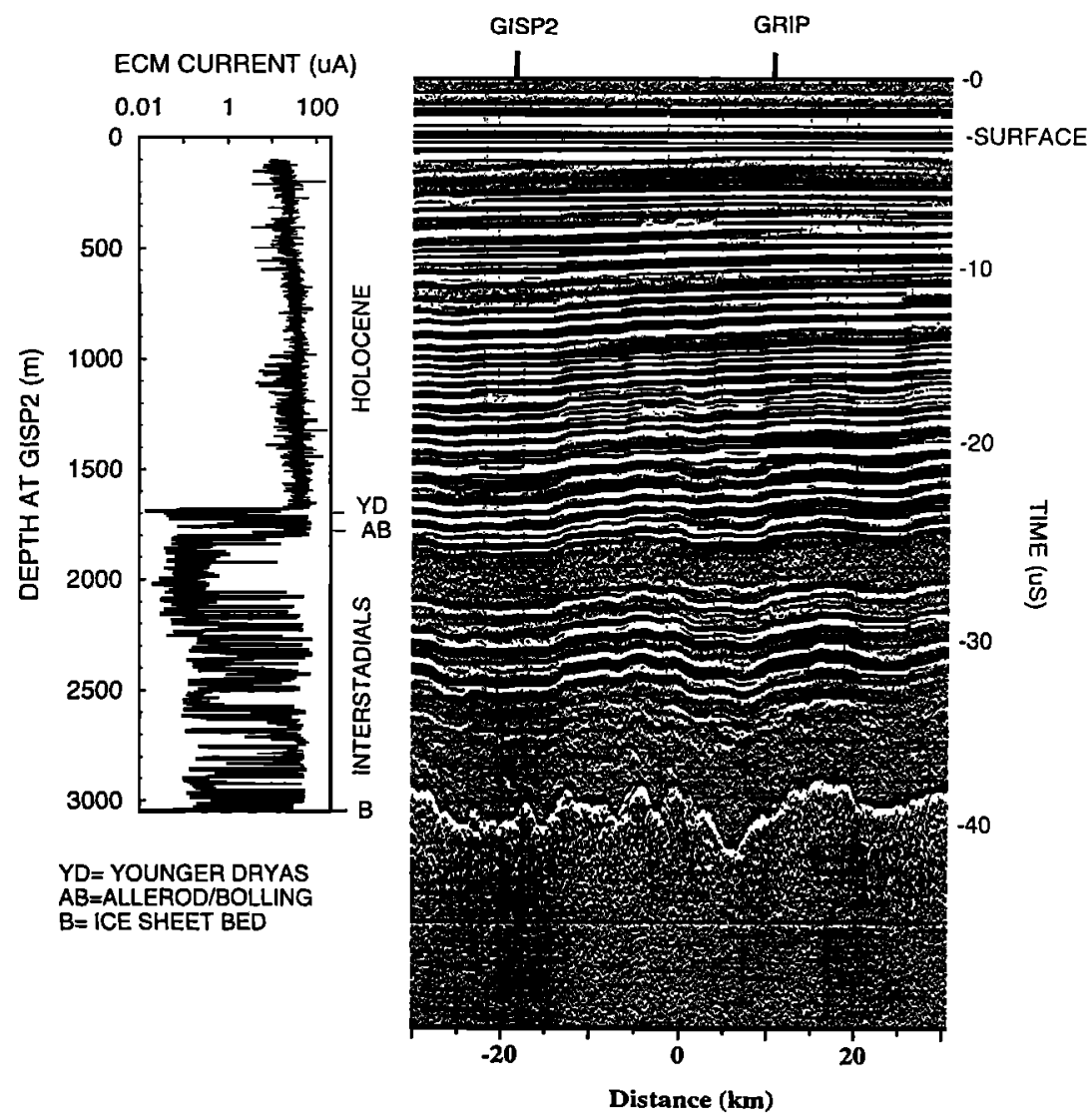

Figure 7. A comparison of the GISP2 ECM and airborne radar [Jacobel and Hodge, 1995] shows the strong reflections associated with the Dansgaard/Oeschger interstadial events from 2100 to $2500 \mathrm{~m}$. Signal attenuation or scattering associated with folding obscures reflections from the strong contrasts in electrical conductivity below $2500 \mathrm{~m}$. There are no detectable reflections from within the alkaline ice at the end of the Wisconsin. Ice containing the Younger Dryas period is too thin to produce a consistently identifiable signal.

the ice was made to determine what the ECM current would be at a temperature of $-20^{\circ} \mathrm{C}$ [Taylor et al., 1992]. When an ice core was undergoing a temperature transition, the surface temperature did not represent the temperature of the volume being measured. There may be sections $2-50 \mathrm{~m}$ in length that have a several percent variation from the correct ECM current because of the temperature uncertainty. We now hold the ice at a constant temperature for 24 hours prior to measurement to avoid this complication. An error of several percent over hundreds of meters may have occurred due to variations in the surface conditions of the electrodes. The electrodes are now filed daily to assure a consistent surface condition. Between 1100 and $1400 \mathrm{~m}$ the core quality was low and there were numerous small pieces of ice per 2-m segment of core. There was also an intermittent problem with the electrical grounding of the system. Both of these factors reduced the data quality in this section. The preamplifier was changed at a depth of $2250 \mathrm{~m}$, which appears to have altered the response of the ECM instrumentation at levels below 0.1 microamps. This results in an artifact which incorrectly suggests that stadial periods have a slightly lower ECM current above $2250 \mathrm{~m}$ than below $2250 \mathrm{~m}$. The design of the preamplifier has been stabilized to prevent this from recurring. No attempt was made to calibrate the response of the GISP2 ECM record to the acidity of the core. This was not done because only the relative response of the ECM was required for the interpretation approaches we employed.
The ECM played a significant role in the interpretation of the GISP2 core. The high spatial resolution allowed the ECM to provide data on a spatial scale that most other measurements were unable to obtain. An additional benefit of the ECM was that it gave results in real time during the core processing. This allowed investigators to modify sampling protocols to optimize the sampling when particularly significant sections of the core were being processed.

Acknowledgments. This work was supported by a grant from the Office of Polar Programs, United States National Science Foundation. We wish to thank the Polar Ice Coring Office (previously at the University of Alaska) for logistic and drilling support, the TAG 109th Air Force National Guard for air support, and the Science Management Office (University of New Hampshire) for coordinating the GISP2 Program. The assistance of Lisa Barlow, Randy Borys, Georgie Doyle, Jim Litchfield, Todd Miheve, and Mike Savage with data collection is greatly appreciated.

\section{References}

Alley, R. B., and B. R. Koci, Recent warming in central Greenland?, Ann. Glaciol., 14, 6-8, 1990.

Alley, R. B., et al., Abrupt increase in Greenland snow accumulation at the end of the Younger Dryas event, Nature, 362, 527-529, 1993. Alley, R. B., A. J. Gow, S. J. Johnsen, J. Kipfstuhl, D. A. Meese, and T. Thorsteinsson, Comparison of deep ice cores, Nature, 373, 393394, 1995.

Chylek, P., B. Johnson, P. A. Damiano, K. C. Taylor, and P. L. Clem- 
ent, Biomass burning record and black carbon concentration in the GISP2 ice core, Geophys. Res. Lett., 22(2), 89-92, 1995.

Dansgaard, W., et al., Evidence for general instability of past climate from a 250-kyr ice-core record, Nature, 364, 218-220, 1993.

Grootes, P. M., M. Stuiver, J. W. C. White, S. Johnsen, and J. Jouzel, Comparison of oxygen isotope records from the GISP2 and GRIP Greenland ice cores, Nature, 366, 552-554, 1993.

Hammer, C. U., Acidity of polar ice cores in relation to absolute dating, past volcanism, and radio-echoes, J. Glaciol., 25(93), 359372,1980 .

Hov, O., and B. A. Hjøllo, Transport distance of ammonia and ammonium in northern Europe, J. Geophys. Res., 99(D9), 18,735$18,748,1994$.

Jacobel, R. W., and S. M. Hodge, Radar internal layers from the Greenland summit, Geophys. Res. Lett., 22(5), 587-590, 1995.

Mayewski, P. A., L. D. Meeker, M. C. Morrison, M. S. Twickler, S. I. Whitlow, K. K. Ferland, D. A. Meese, M. R. Legrand, and J. P. Steffenson, Greenland ice core "signal" characteristics: An expanded view of climate change, J. Geophys. Res., 98(D7), 12,83912,847, 1993a.

Mayewski, P. A., G. Holdsworth, M. J. Spencer, S. Whitlow, M. Twickler, M. C. Morrison, K. K. Ferland, and L. D. Meeker, Ice core sulfate from three northern hemisphere sites: Source and temperature forcing implications, Atmos. Environ. Part A, 27(17/18), 29152919, 1993b.

Mayewski, P. A., et al., Changes in atmospheric circulation and ocean ice cover over the North Atlantic during the last 41,000 years, $S$ cience, 263, 1747-1751, 1994.

Meese, D. A., A. J. Gow, P. Grootes, P. A. Mayewski, M. Ram, M. Stuiver, K. C. Taylor, E. D. Waddington, and G. A. Zielinski, The accumulation record from the GISP2 core as an indicator of climate change throughout the Holocene, Science, 266, 1680-1682, 1994

Moore, J. C., E. W. Wolff, H. B. Clausen, and C. U. Hammer, The chemical basis for the electrical stratigraphy of ice, J. Geophys. Res., 97(B2), 1887-1896, 1992.

Neftel, A., M. Andrée, J. Schwander, B. Satuffer, and C. U. Hammer, Measurements of a kind of DC-conductivity on cores from Dye 3 , in Greenland Ice Core: Geophysics, Geochemistry, and the Environment, Geophys. Monogr. Ser., vol. 33, edited by C. C. Langway Jr., H. Oeschger, and W. Dansgaard, pp. 32-38, AGU, Washington, D. C., 1985.

Ram, M., and M. Illing, Polar ice stratigraphy from laser-light scattering: Scattering from meltwater, J. Glaciol., 40(136), 504-508, 1994.

Ram, M., and G. Koenig, Continuous dust concentration profile of pre-Holocene ice from the Greenland Ice Sheet Project 2 ice core:
Dust stadials, interstadials, and the Eemian, J. Geophys. Res., this issue.

Taylor, K., R. Alley, J. Fiacco, P. Grootes, G. Lamorey, P. Mayewski, and $\mathrm{M}$. J. Spencer, Ice-core dating and chemistry by direct-current electrical conductivity, J. Glaciol., 38(130), 325-332, 1992.

Taylor, K. C., G. W. Lamorey, G. A. Doyle, R. B. Alley, P. M. Grootes, P. A. Mayewski, J. W. C. White, and L. K. Barlow, The 'flickering switch' of late Pleistocene climate change, Nature, 361, 432-436, 1993a.

Taylor, K. C., C. U. Hammer, R. B. Alley, H. B. Clausen, D. DahlJensen, A. J. Gow, N. S. Gundestrup, J. Kipfstuhl, J. C. Moore, and E. D. Waddington, Electrical conductivity measurements from the GISP2 and GRIP Greenland ice cores, Nature, 366, 549-552, 1993b.

Taylor, K. C., P. A. Mayewski, M. S. Twickler, and S. I. Whitlow, Biomass burning recorded in the GISP2 ice core: A record from eastern Canada?, Holocene, 6(1), 1-6, 1996.

Whitlow, S., P. A. Mayewski, G. Holdsworth, M. S. Twicker, and J. E. Dibb, An ice core based record of biomass burning in North America, 1750-1980, Tellus Ser. B., 46, 239-242, 1994.

Wolff, E. W., J. C. Moore, H. B. Clausen, C. U. Hammer, J. Kipfstuhl, and $\mathrm{K}$. Fuhrer, Long-term changes in the acid and salt concentrations of the Greenland Ice Core Project ice core from electrical stratigraphy, J. Geophys. Res., 100(D8), 16,249-16,263, 1995.

Zielinski, G. A., P. A. Mayewski, L. D. Meeker, S. Whitlow, M. S. Twickler, M. Morrison, D. A. Meese, A. J. Gow, and R. B. Alley, Record of volcanism since 7000 B.C. from the GISP2 Greenland ice core and implications for the volcano-climate system, Sclence, 264, 948-952, 1994.

Zielinski, G. A., P. A. Mayewski, L. D. Meeker, S. Whitlow, M. S. Twickler, and $\mathrm{K}$. Taylor, Potential atmospheric impact of the Toba mega-eruption $\sim 71,000$ years ago, Geophys. Res. Lett., 23(8), 837$840,1996$.

R. B. Alley, Earth System Science Center and Department of Geosciences, Pennsylvania State University, University Park, PA 16802.

G. W. Lamorey and K. C. Taylor, Desert Research Institute, Water Resources Center, University and Community College System of Nevada, Box 60220, Reno, NV 89506. (e-mail: kendrick@mayey.dri.edu)

P. Mayewski, Glacier Research Group, Institute for the Study of Earth, Oceans and Space, University of New Hampshire, Durham, NH 03824 .

(Received December 29, 1995; revised July 23, 1996; accepted July 23, 1996.) 